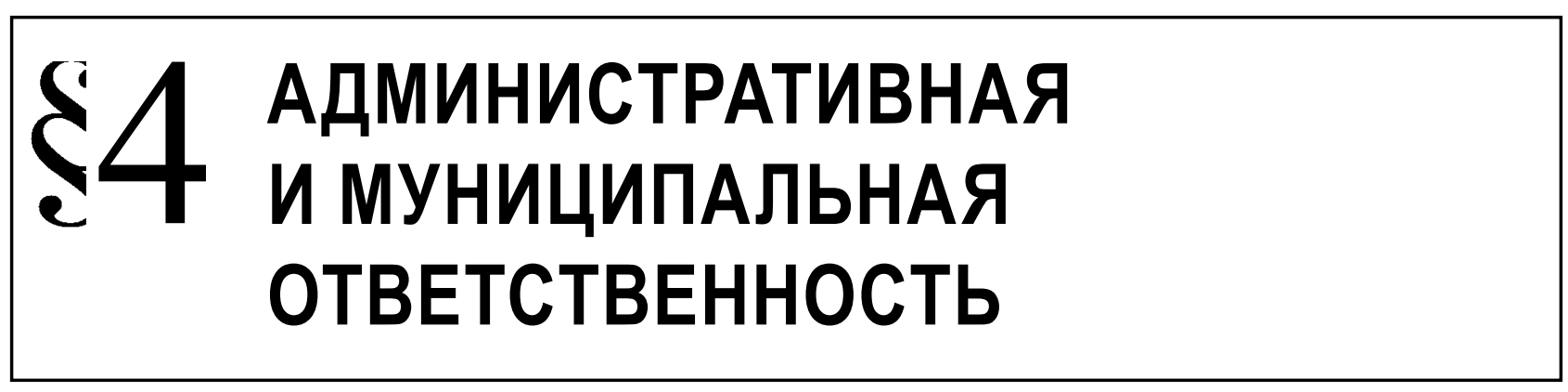

Дресвянникова Е.А.

\title{
ВОПРОСЫ ОБЕСПЕЧЕНИЯ ИСПОЛНЕНИЯ ПОСТАНОВЛЕНИЙ ПО ДЕЛАМ ОБ АДМИНИСТРАТИВНЫХ ПРАВОНАРУШЕНИЯХ В ОБЛАСТИ ДОРОЖНОГО ДВИЖЕНИЯ
}

Аннотация. Нормы, устанавливающие административную ответственность, становятся формальными, если принятые решения по делам об административных правонарушениях не исполняются. Проведенный автором анализ правоприменительной практики показывает, что в тех случаях, когда нецелесообразно назначать итраф (особенно если размер административного итрафа соответствует штрафам, назначаемым за отдельные виды уголовных наказаний), целесообразно назначить иной вид административного наказания и тем самым достигнуть цели его назначения - предупреждения совершения новых правонарушений как самими правонарушителями, так и другими лицами. Большие суммы штрафов, взыскаемость которых это огромная проблема исполнительного производства, необходимо заменить на иные, соразмерные виды наказаний.В рассматриваемой статье автором высказано предложение о дополнении статьи 20.25 КоАП РФ частью 11, предусматривающей ответственность за уклонение от исполнения иного административного наказания, назначенного за нарушение порядка пользования специальным правом, предоставленного физическому лицу. Считаем, что тем самым адекватность назначенного наказания за уклонение от исполнения административного наказания будет способствовать реализации принципа неотвратимости наказания. Сбор и обработка данных проводились путем применения фрормально-логического, диалектического методов, а также сравнительно-правового, логического, статистического анализа дел об административных правонарушениях в области дорожного движения. Ужесточение административной ответственности за правонарушения в области дорожного движения приводит к снижению лишь отдельных их видов, не решая проблем ни в сокращении дорожно-транспортных происшествий и как следствие числа погибших и раненых людей, ни в области исполнения назначенных административных наказаний за данные виды правонарушений.В правоприменительной деятельности сотрудников Госавтоинспекции административное исполнительное производство широко используется не только в рамках соблюдения принципа неотвратимости наказания, но и как профилактическая мера по обеспечению безопасности дорожного движения. Именно поэтому одним из приоритетных направлений деятельности в данной сфере является разработка предложений по урегулированию порядка обеспечения исполнения постановлений по делам об административных правонарушениях. Исследование направлено на повышение эффрективности деятельности Госавтоинспекции Российской Федерации по исполнению назначенных административных наказаний за правонарушения в области дорожного движения. Проанализирована правоприменительная практика по исполнению назначенных административных наказаний за правонарушения в области дорожного движения и сформулированы рекомендации по совершенствованию законодательства об административной ответственности в области дорожного движения.

Ключевые слова: производство, исполнение, постановление, итраф, правонарушение, наказание, административная ответственность, лищение специального права, физическое лицо, безопасность дорожного движения. Review. The norms imposing administrative responsibility are formal if the decisions are not executed. The author analyzes law enforcement practice and concludes that in case it is not reasonable to impose a fine (particularly when an administrative fine equals to fines for some types of criminal offences), it is reasonable to impose another type of administrative punishment, thus achieving the main aim - prevention of new offences by the same offender and by other 
persons. Large fines which are very difficult to exact should be replaced with other proportionate types of punishment. The author of the paper suggests amending the art. 20.25 of the Code of Administrative Offences of the Russian Federation with a part 11, containing the responsibility for the evasion of administrative punishment imposed for special rights abuse. The author argues that the adequacy of an imposed punishment for the evasion of administrative punishment will promote the principle of unavoidability of punishment. For data collection and processing the author uses the formal-logical and the dialectical methods, and the comparative-legal, logical and statistical analysis of the cases of administrative offences in the sphere of traffic safety. The toughening of administrative responsibility for offences in the sphere of traffic safety leads only to the decrease of some types of such offences, but it solves neither the problems of the quantity of traffic accidents and the amount of victims, nor the problems in the sphere of the imposed punishment execution. In law enforcement practice of traffic officers administrative executive proceedings are widely used not only for the observance of the principle of unavoidability of punishment, but also as a preventive measure for traffic safety provision. Therefore, the execution of decisions on administrative offences is one of the priority directions in this sphere. This research is aimed at the Russian traffic police efficiency enhancement in the sphere of administrative punishment for traffic violation execution. The author analyzes law enforcement practice of the imposed administrative punishment execution and offers recommendations for legislation enhancement in the sphere of administrative responsibility for traffic violation.

Keywords: natural person, deprivation of a special right, proceedings, execution, decision, fine, offence, punishment, administrative responsibility, traffic safety.

$\mathrm{C}$ остояние аварийности на автомобильном транспорте - одна из острейших юридических, социально-экономических и политических проблем в нашем государстве. За одиннадцать месяцев 2014 года в результате 181540 дорожнотранспортных происшествий в Российской Федерации погибло 24423 человек, ранено 228855 человек [1]. Динамика основных показателей аварийности за последние семь лет принципиальных изменений не претерпевает, что свидетельствует о том, что уровень дорожно-транспортного травматизма в России остается высоким.

Сегодня весь цивилизованный мир озабочен проблемой сохранения жизни и здоровья людей на дорогах и пытается ее решать. Большинством аналитиков Министерства внутренних дел Российской Федерации одной из основных причин аварийности на дорогах указывается противоправное поведение водителей транспортных средств.

Решение же законодателя Российской Федерации об ужесточении административной ответственности в 2013 году привело к снижению лишь отдельных видов правонарушений в области дорожного движения. Однако данные изменения не уменьшили проблем в области исполнения назначенных административных наказаний за данные виды правонарушений.

Бесспорно, нормы, устанавливающие административную ответственность, становятся формальными, если принятые решения по делам об административных правонарушениях не исполняются. Безнаказанность же правонарушителей обесценивает авторитет правоохранительной систе- мы России. Именно поэтому на современном этапе развития правоприменительной деятельности сотрудников Госавтоинспекции административное исполнительное производство широко используется не только в рамках соблюдения принципа неотвратимости наказания, но и как профилактическая мера по обеспечению безопасности дорожного движения.

Действительно, административная ответственность имеет в своем арсенале удобную, а значит привлекательную меру - штраф [2]. Однако данным видом наказания не предупредить совершения правонарушений в области безопасности дорожного движения. У населения нашей страны необходимо формировать нетерпимость к правонарушениям в области дорожного движения. Для достижения этой цели необходимо обеспечить надлежащее исполнение постановлений по делам об административных правонарушениях, а именно реализовать принцип неотвратимости наказания путем его исполнения.

Не случайно, за совершение административных правонарушений, предусмотренных частями 1,2 и 4 статьи 12.8, частью 1 статьи 12.26, частью 3 статьи 12.27 Кодекса Российской Федерации об административных правонарушениях (далее - КоАП РФ) лишение специального права в виде права управления транспортным средством применяется в качестве дополнительного административного наказания. Полагаем, что законодатель усматривал в этом, прежде всего, ужесточение наказания по наиболее «опасным» правонарушениям в области дорожного движения. 
Безусловно, с внесением изменений в КоАП РФ была устранена коллизия по исполнению наказания, назначенного по указанным правонарушениям. Ранее, на основании части 4.1 статьи 32.6 КоАП РФ правонарушитель, исполнив дополнительный вид наказания (лишение специального права в виде права управления транспортным средством), но, уклонившись от исполнения основного наказания (штрафа), сохранял право на возврат водительского удостоверения по истечении срока лишения специального права.

В настоящее время (буквально с 15 ноября 2014 года) по истечении срока лишения специального права за совершение административных правонарушений, предусмотренных главой 12 КоАП РФ, водительское удостоверение или удостоверение тракториста-машиниста (тракториста), изъятые у лица, подвергнутого данному виду административного наказания, возвращаются после проверки знания им Правил дорожного движения и после уплаты в установленном порядке наложенных на него административных штрафов за административных правонарушения в области дорожного движения, а за совершение административных правонарушений, предусмотренных частями 1 и 4 статьи 12.8, частью 1 статьи 12.26, частью 3 статьи 12.27 КоАП РФ, также медицинского освидетельствования данного лица на наличие медицинских противопоказаний к управлению транспортным средством.

Таким образом, законодатель постарался разрешить, возникшую за год применения части 4.1 статьи 32.6 КоАП РФ, проблему по исполнению наказания, назначенного по указанным правонарушениям.

Однако, это лишь часть решения проблемы исполнения постановлений по делам об административных правонарушениях в области дорожного движения.

Так, например, за десять месяцев 2014 года в Республике Татарстан к административной ответственности по статье 20.25 КоАП РФ «Уклонение от исполнения административного наказания» за неисполнение постановлений по делам об административных правонарушениях в области дорожного движения привлечено 17330 граждан, из них с назначением наказания в виде наложения административного штрафа в двукратном размере суммы неуплаченного административного штрафа 8107 граждан, с назначением административного наказания в виде ареста 5697 граждан и обязательных работ 3526 граждан [3].
При этом двукратный размер суммы неуплаченного административного штрафа применялся лишь в части тех штрафов, размер которых не превышал пяти тысяч рублей.

Анализ судебной практики [4] назначения наказания по статье 20.25 КоАП РФ в двукратном размере суммы неуплаченного административного штрафа показал, что в части тех статей 12 главы КоАП РФ, в которых размер штрафных санкций свыше 5 тысяч рублей (и более того, по ч.2, 3 ст. 12.7; ч.3 ст. 12.8 КоАП РФ - 30 тысяч рублей) на сегодняшний день нет.

Данная проблема возникает в частности и по привлечению по статье 20.25 КоАП РФ тех лиц, в отношении которых действуют ограничения применения отдельных видов административных наказаний - ареста, обязательных работ. К ним, в соответствии с частью 1 статьи 3.9 КоАП РФ относятся: беременные женщины, женщины, имеющие детей в возрасте до четырнадцати лет, лица, не достигшие возраста восемнадцати лет, инвалиды I и II групп, военнослужащие, граждане, призванные на военные сборы, а также имеющие специальные звания сотрудники органов внутренних дел, органов и учреждений уголовно-исполнительной системы, Государственной противопожарной службы, органов по контролю за оборотом наркотических средств и психотропных веществ и таможенных органов.

Кроме того, с 15 ноября 2014 года административный арест, предусмотренный частью 1 статьи 20.25 КоАП РФ, не может применяться к лицу, которое не уплатило административный штраф за совершение административного правонарушения, предусмотренного главой 12 КоАП РФ и зафиксированного с применением работающих в автоматическом режиме специальных технических средств, имеющих функции фото- и киносъемки, видеозаписи, или средств фото- и киносъемки, видеозаписи.

Таким образом, к ним возможно применение лишь двукратного размера суммы неуплаченного административного штрафа (за неуплату штрафа по ч.2, 3 ст. 12.7; ч.3 ст. 12.8 КоАП РФ данная сумма будет составлять 60 тысяч рублей).

Федеральным законом от 14.10.2014 г. № 307ФЗ внесено дополнение в часть 2 статьи 2.5 КоАП РФ, расширяющее порядок привлечения военнослужащих, граждан, призванных на военные сборы, а также имеющих специальные звания сотрудников органов внутренних дел, органов и учреждений уголовно-исполнительной системы, Государ- 
ственной противопожарной службы, органов по контролю за оборотом наркотических средств и психотропных веществ и таможенных органов к административной ответственности на общих основания по части 1 статьи 20.25 КоАП РФ.

При этом в случае привлечения к административной ответственности по статье 20.25 КоАП РФ сержантов, старшин, солдат и матросов, проходящих военную службу по призыву, а также курсантов военных профессиональных образовательных организаций и военных образовательных организаций высшего образования до заключения с ними контракта о прохождении военной службы возможно применение только дисциплинарного взыскания, так как к ним не применимы ни штраф (ч. 6 ст. 3.5 КоАП РФ), ни арест (ч.1 ст. 3.9 КоАП РФ), ни обязательные работы (ч.3 ст. 3.13 КоАП РФ).

Получается, привлечь можно, но наказания, предусмотренные санкцией данной статьи к ним не применимы.

На наш взгляд, позиция законодателя в ужесточении наказаний за административные правонарушения в области дорожного движения, видится в ожидании достижения целей частной превенции - опыт пережитого административного наказания удержит лицо, привлеченное к административной ответственности от совершения нового правонарушения. Но стоит напомнить, что эффективность наказания больше зависит не от его жестокости, а от его неотвратимости. Еще в 2002 году в ежегодном Послании к Федеральному Собранию Президент России подчеркнул, что «наша главная цель - добиться неотвратимости наказания, а не его чрезмерной суровости» [5].

В подтверждение этому, стоит отметить, что как бы законодатель не увеличивал размеры штрафов за правонарушения в области дорожного движения, число нарушений снижается лишь на непродолжительный период времени, а в последующем происходит привыкание участников дорожного движения к новым санкциями.

Бесспорно, более опасные деяния должны наказываться более строго - и, наоборот, менее опасные правонарушения должны предусматривать менее строгое наказание. Однако введение законодателем достаточно высоких и недеференцированных по размеру штрафов ставит субъектов административной юрисдикции в положение, не позволяющим им учитывать ни характер совершенного правонарушения, ни личность виновного, а также его имущественное положение, и в зависимости от этого определить размер штрафа.
Возникает убежденность, что обеспечение исполнения назначенных наказаний за правонарушения в области дорожного движения во многом зависит на сегодняшний день от адекватности наказания.

Проведенный анализ правоприменительной практики показывает, что в тех случаях, когда нецелесообразно назначать штраф (особенно если размер административного штрафа соответствует штрафам, назначаемым за отдельные виды уголовных наказаний), целесообразно назначить иной вид административного наказания и тем самым достигнуть цели его назначения - предупреждения совершения новых правонарушений как самими правонарушителями, так и другими лицами.

Реализация указанной цели в аспекте общей и частной превенции обеспечивается посредством неотвратимости наказания и за счет введения таких мер юридической ответственности, которые, будучи соразмерными и справедливыми, позволяют в конкретных обстоятельствах стимулировать участников правовых отношений к правомерному поведению.

Однако, в последнее время, взятый законодателем курс на увеличение размеров административных санкций не согласуется с общеправовыми принципами гуманизма, справедливости и индивидуализации ответственности.

С учетом изложенного, на наш взгляд, для обеспечения исполнения административных наказаний по правонарушениям в области дорожного движения, было бы целесообразным внести изменения в статью 20.25 КоАП РФ, дополнив частью $1^{1}$ следующего содержания: «Уклонение от исполнения иного административного наказания, назначенного за нарушение порядка пользования специальным правом, предоставленного физическому лицу, - влечет административный арест на срок до тридцати суток, либо лишение специального права на срок до двух лет».

Данная норма согласуется с частью 1 статьи 3.8 КоАП РФ, которая в 2013 году дополнена содержанием следующего характера «Лишение физического лица ранее предоставленного ему специального права устанавливается также за уклонение от исполнения иного административного наказания, назначенного за нарушение порядка пользования этим правом, в случаях, предусмотренных статьями Особенной части настоящего Кодекса».

В часть 1 стати 3.9 КоАП РФ соответственно необходимо внести изменения, после слов «или правового режима контртеррористической опе- 
рации» дополнить словами «за уклонение от исполнения иного административного наказания, назначенного за нарушение порядка пользования специальным правом либо...до тридцати суток».

Считаем, что тем самым адекватность назначенного наказания за уклонение от исполнения административного наказания будет способствовать реализации принципа неотвратимости наказания. Большие суммы штрафов, взыскаемость которых это огромная проблема исполнительного производства, будут заменены на иные, соразмерные виды наказаний.

Резюмируя, отметим, что Конституционный Суд РФ определил, что административная ответ- ственность по части 1 статьи 20.25 КоАП РФ не является мерой принудительного исполнения судебного акта и актов органов должностных лиц (статья 68 Федерального закона «Об исполнительном производстве»), так как призвана стимулировать правонарушителей к добровольной уплате штрафа - без использования механизма принудительного исполнения постановлений по делам об административных правонарушениях [6]. На деле же получается иначе, поэтому, на наш взгляд, введение данной нормы будет способствовать обеспечению принципа неотвратимости наказания, в частности - обеспечения исполнения постановлений по делам об административных правонарушениях в области дорожного движения.

\section{Библиография:}

1. Официальный сайт Госавтоинспекции МВД России: htpp://www.gibdd.ru (Дата обращения 17 декабря 2014 г.).

2. Сорокин В. Д. Парадоксы Кодекса Российской Федерации об административных правонарушениях // Административное право и процесс. - 2014.-№ 3. - С.6.

3. Единый отчет за десять месяцев 2014 года по административной практике УГИБДД МВД по Республике Татарстан.

4. Обобщение судебной практики по административным делам Интернет ресурс: http://supcourt.ru; perev2.kodms. ru. (Дата обращения 25 ноября 2014 г.).

5. Послание Президента Российской Федерации Федеральному Собранию Российской Федерации «России надо быть сильной и конкурентоспособной» // Российская газета. - 2002. - № 71. - С. 1-2.

6. Определение Конституционного Суда РФ от 07.10.2014 г. № 2323-0 «По запросу мирового судьи судебного участка № 56 Нерчинского района Забайкальского края о проверке конституционности положений части 1 статьи 4.5 и части 1 статьи 20.25 Кодекса Российской Федерации об административных правонарушениях» // Правовая система КонсультантПлюс (Дата обращения 26.11.2014 г.).

7. Куракин А.В. Компетенция полиции в сфере реализации законодательства об административных правонарушениях // NB: Административное право и практика администрирования. - 2013. - № 4. - C. 28-48 // URL: http:// www.e-notabene.ru/al/article_8841.html

8. Паньшин Д.Л., Дресвянникова Е. А. Сроки и порядок исполнения постановления о назначении административного наказания в виде штрафа // Административное и муниципальное право. - 2013.-№ 9.- C. 898-900. DOI: 10.7256/1999-2807.2013.9.9099.

9. Сорокин В. Д. Парадоксы Кодекса Российской Федерации об административных правонарушениях // Административное право и процесс. - 2014.-№ 3. - С.6

10. Трунов И.Л. Проблемы безопасности дорожного движения // Административное и муниципальное право.-2013.8.-C. 797-801. DOI: 10.7256/1999-2807.2013.8.9369.

11. Костенников М.В., Куракин А.В. К вопросу об основании административной ответственности в российском праве // NB: Административное право и практика администрирования.-2013.-10.-C. 75-88. DOI: 10.7256/23069945.2013.10.10153. URL: http://www.e-notabene.ru/al/article_10153.html

12. Долгих И.П., Супонина Е.А. К вопросу об оптимизации отдельных видов административных наказаний // Юридические исследования.-2014.-10.-C. 1-18. DOI: 10.7256/2305-9699.2014.10.13225. URL: http://www.e-notabene. $\mathrm{ru} / \mathrm{lr} /$ article_13225.html

\section{References (transliterated):}

1. Ofitsial'nyi sait Gosavtoinspektsii MVD Rossii: htpp://www.gibdd.ru (Data obrashcheniya 17 dekabrya 2014 g.).

2. Sorokin V. D. Paradoksy Kodeksa Rossiiskoi Federatsii ob administrativnykh pravonarusheniyakh // Administrativnoe pravo i protsess. - 2014.-№ 3. - S.6.

3. Edinyi otchet za desyat' mesyatsev 2014 goda po administrativnoi praktike UGIBDD MVD po Respublike Tatarstan.

4. Obobshchenie sudebnoi praktiki po administrativnym delam Internet resurs: http://supcourt.ru; perev2.kodms.ru. (Data obrashcheniya 25 noyabrya 2014 g.).

5. Poslanie Prezidenta Rossiiskoi Federatsii Federal'nomu Sobraniyu Rossiiskoi Federatsii «Rossii nado byt' sil'noi i konkurentosposobnoi» // Rossiiskaya gazeta. - 2002. - № 71. - S. 1-2. 
6. Opredelenie Konstitutsionnogo Suda RF ot 07.10.2014 g. № 2323-O «Po zaprosu mirovogo sud'i sudebnogo uchastka № 56 Nerchinskogo raiona Zabaikal'skogo kraya o proverke konstitutsionnosti polozhenii chasti 1 stat'i 4.5 i chasti 1 stat'i 20.25 Kodeksa Rossiiskoi Federatsii ob administrativnykh pravonarusheniyakh» // Pravovaya sistema Konsul'tantPlyus (Data obrashcheniya 26.11.2014 g.).

7. Kurakin A.V. Kompetentsiya politsii v sfere realizatsii zakonodatel'stva ob administrativnykh pravonarusheniyakh // NB: Administrativnoe pravo i praktika administrirovaniya. - 2013. - № 4. - C. 28-48 // URL: http://www.e-notabene.ru/ al/article_8841.html

8. Pan'shin D.L., Dresvyannikova E. A. Sroki i poryadok ispolneniya postanovleniya o naznachenii administrativnogo nakazaniya v vide shtrafa // Administrativnoe i munitsipal'noe pravo. - 2013.-№ 9. - S. 898-900. DOI: 10.7256/19992807.2013.9.9099.

9. Sorokin V. D. Paradoksy Kodeksa Rossiiskoi Federatsii ob administrativnykh pravonarusheniyakh // Administrativnoe pravo i protsess. - 2014.-№ 3. - S.6

10. Trunov I.L. Problemy bezopasnosti dorozhnogo dvizheniya // Administrativnoe i munitsipal'noe pravo.-2013.-8.C. 797-801. DOI: 10.7256/1999-2807.2013.8.9369.

11. Kostennikov M.V., Kurakin A.V. K voprosu ob osnovanii administrativnoi otvetstvennosti v rossiiskom prave // NB: Administrativnoe pravo i praktika administrirovaniya.-2013.-10.-C. 75-88. DOI: 10.7256/2306-9945.2013.10.10153. URL: http://www.e-notabene.ru/al/article_10153.html

12. Dolgikh I.P., Suponina E.A. K voprosu ob optimizatsii otdel'nykh vidov administrativnykh nakazanii // Yuridicheskie issledovaniya.-2014.-10.-C. 1-18. DOI: 10.7256/2305-9699.2014.10.13225. URL: http://www.e-notabene.ru/lr/ article_13225.html 